\title{
Quarentena da COVID-19 no Brasil: necessidade ou política do excesso contra o desconhecido? Uma crítica ao plano brasileiro de contingência, frente às orientações do relatório do Imperial College Team
}

\author{
Walner Mamede \\ Doutor em Psicologia; Professor Adjunto na Universidade Paulista-Unip; Analista em Ciência e Tecnologia na \\ Capes, onde trabalha com avaliação de políticas públicas; Diretor no Sindicato dos Gestores em C\&T-SindGCT \\ $\triangle$ walner.mamede@capes.gov.br
}

\begin{abstract}
Resumo:
O ensaio apresenta uma reflexão acerca de variáveis, aparentemente, não valoradas, na luta contra o coronavírus, sem pretender uma resposta definitiva diante da ausência de dados científicos. A discussão foi realizada a partir de informações fornecidas na Internet por especialistas, às quais adicionaram-se os poucos dados científicos existentes sobre a crise atual, discutindo a relação entre o plano nacional brasileiro contra o COVID 19, as informações da OMS e o Relatório do Imperial College. Assim, inferiu-se a necessidade de melhorar informações sobre o contexto brasileiro para melhorar também a política de combate ao COVID-19 em território nacional, sem negligenciar nosso compromisso como nação-membro da comunidade internacional, mas indicando a importância de se contextualizar a política de acordo com as nossas próprias necessidades, em nome da eficiência e da economicidade.
\end{abstract}

Palavras-chave: COVID-19; plano de contingência; pandemia; avaliação de política; Saúde Pública.

COVID-19 quarantine in Brazil: need or excess policy against the unknown? A critique to the Brazilian contingency plan, against the guidelines of the Imperial College report

\begin{abstract}
:
This essay aim to talk about variables that were not approached, yet, or just was partially approched, on the fight against coronavirus, analyzing your pertinence, but whithout to give a definitive answer, in face of the absence of scientific datas. Like this, we perform a discussion from informations that exist into of the internet gave for experts, added of the few scientifics datas existent about atual crise, discussing relationship between brazlian national plan against COVID 19, WHO's informations and Imperial College COVID-19 Response Team's Report. From this, we infer the need to improve the informations about brazilian contexto to improve too the fight COVID-19 policy into national territory, without negligence to the combat, neither disrupt our commitment, like intenational community member, but contextualizing our policys according with ours own needs for its best efficiency.
\end{abstract}

Keywords: COVID-19; contingency plan; pandemy; policy assessment; Public Health. 


\section{Cuarentena de COVID-19 en Brasil: ¿necesidad o política excesiva contra lo desconocido? Una crítica al plan de contingencia brasileño, en contra de las pautas del informe del Imperial College Team}

\section{Resumen:}

El ensayo presenta una reflexión sobre variables, aparentemente, no valoradas, en la lucha contra el coronavirus, sin pretender una respuesta definitiva en ausencia de datos científicos. La discusión se basó en información proporcionada en Internet por especialistas, a la que se agregaron los pocos datos científicos existentes sobre la crisis actual, discutiendo la relación entre el plan nacional brasileño contra COVID 19, la información de la OMS y el Informe del Colegio Imperial. Por lo tanto, se infirió la necesidad de mejorar la información sobre el contexto brasileño para mejorar también la política de lucha contra COVID-19 en el territorio nacional, sin descuidar nuestro compromiso como nación miembro de la comunidad internacional, pero indicando la importancia de contextualizar la política. de acuerdo a nuestras propias necesidades, en nombre de la eficiencia y la economía.

Palabras clave: COVID-19; plan de contingencia; pandemia; evaluación de políticas; Salud pública.

\section{INTRODUÇÃO}

Em 29 de dezembro de 2019, um hospital em Wuhan, na China, admitiu quatro pessoas com pneumonia. Essas pessoas possuíam em comum o local de trabalho, um mercado de animais de caça para consumo humano, de Huanan. Após notificação ao Centro de Controle de Doenças ( $C D C)$, foram identificados outros pacientes que compartilhavam o mesmo ambiente de trabalho. A partir desse momento uma série de ações foram adotadas no país e, poucas semanas depois, o mundo se via às voltas com uma ameaça de pandemia por um vírus desconhecido, logo identificado como SARS-CoV-2, responsável por uma modalidade de gripe acompanhada pela Síndrome Respiratória Aguda Severa (SARS), um variante dos 36 tipos de coronavírus e pertencente à família Coronaviridae, dentre os quais encontramos o SARS-CoV, responsável pelo surto ocorrido entre 2002-2003, também, na China (CHENG et al, 2007; BRASIL, 2020a; WU; MCGOOGAN, 2020)

Diante dos vários casos identificados fora da China, diversos países do mundo iniciaram, sob orientação da Organização Mundial de Saúde-OMS (WHO, 2020a), procedimentos de contingência para combater a ameaça. Frente à carência de dados e evidências científicas, os protocolos adotaram procedimentos severos para restrição dos contatos sociais e, consequentemente, da transmissão, optando pela possibilidade de errar por excesso. Nesse sentido, uma equipe do Imperial College, na Grã-Bretanha, especialmente, destacada para combater o SARS-CoV-2 ou COVID-19, produziu um relatório baseado no estudo de casos advindos da China, Reino Unido e Itália, com a intenção de orientar a adoção 
de medidas na própria Grã-Bretanha (GB) e nos Estados Unidos (EUA), mas extensível a qualquer país de alta renda e economia estável, capaz de implementar e sustentar as medidas necessárias, pelo tempo adequado (FERGUSON et al, 2020). Com o surgimento oficial do primeiro caso brasileiro*, em 26-27 de fevereiro de 2020 (WHO, 2020b), seguindo as diretrizes internacionais e as próprias diretrizes para situações epidêmicas, o Brasil desenvolveu um plano de contingência, por meio do Centro de Operações de Emergência em Saúde Pública (COE-COVID-19), do Ministério da Saúde (MS), coordenado pela Secretaria de Vigilância em Saúde (SVS) e responsável pelo norteamento das ações em cooperação com o Sistema Único de Saúde-SUS (BRASIL, 2020a), o qual parece não ter orientado as ações implementadas, que se pautaram, predominantemente, nos protocolos internacionais.

O presente ensaio buscará empreender uma reflexão sobre a controvérsia estabelecida acerca da adoção irrestrita das orientações emanadas da OMS e do Imperial College Team Report (ICTR) produzido por Ferguson et al (2020), particularmente, na realidade brasileira, à guisa de uma primeira aproximação avaliativa da política de combate ao coronavírus. Nesse sentido, considerando as esparsas fontes científicas sobre a crise instaurada, buscamos em veículos midiáticos e documentos oficiais informações expressas por especialistas e gestores políticos, cujas referências online são apresentadas para consulta, cotejando-as com fontes científicas disponíveis, na direção das considerações apresentadas, o que demandará certo grau de indulgência na leitura do ensaio, pois algumas de suas fontes não possuem origem em veículos científicos, fugindo, em certa medida, dos padrões de escrita científica, mundialmente, aceitos. Assim, a primeira seção apresenta uma reflexão sobre as orientações, internacionalmente, adotadas como referência. A segunda seção apresenta uma discussão que busca relacionar tais orientações internacionais com as diretrizes do Plano Nacional de Contingência produzido pelo MS, no Brasil, frente a ponderações acerca de variáveis de contexto importantes a serem consideradas. A terceira seção discute a importância de um saneamento da comunicação midiática sobre a COVID-19. Para finalizar, são apresentadas considerações pouco conclusivas, mas, pretensamente, provocativas, acerca da controvérsia, como contribuição ao debate, ainda, imaturo.

\footnotetext{
* Dados epidemiológicos no Brasil em 26/03/2020, segundo a OMS: total de casos=2.433; novos casos=232; total de mortes=57; novas mortes=11. Portanto, um mês após o primeiro caso, o Brasil se tornou o terceiro na América, antecedido de perto pelo Canadá (3.409 casos) e em muito pelos EUA (63.570 casos).
} 


\section{PRINCÍPIOS INTERNACIONAIS DAS AÇÕES DE CONTINGÊNCIA}

Diante da repentina ameaça do novo coronavírus, mecanismos de investigação foram mobilizados por todo o mundo. Antecipando a atual crise, em razão do surto ocorrido entre 2002 e 2003, também na China, Cheng et al (2007) realizaram um estudo, no qual caracterizaram o SARS-CoV, responsável pela Síndrome Respiratória Aguda Severa (SARS), e estabeleceram uma relação entre o consumo e manejo de animais de caça, no sul da China, e seu surgimento entre humanos, o que possui relação, também, com a COVID-19. A apresentação clínica típica da SARS é a pneumonia viral com rápida deterioração respiratória, febre, calafrios, mialgia, mal-estar e tosse improdutiva, sendo a rinorreia e a dor e a inflamação de garganta vistos com menos frequência. Segundo os autores, a transmissão aérea da SARS é considerada incomum, sendo o risco geral de transmissão baixo, em torno de 1 para 156. Os autores apresentaram, também, um caso no qual 22 passageiros, aparentemente, se infectaram em um voo doméstico, na China, nesse período, onde existia um passageiro com SARS. No entanto, em outro voo posterior, um passageiro com SARS viajou entre a China e os países europeus e nenhuma transmissão foi detectada, sugerindo que a transmissão de SARS sem o contato direto com secreção infectada não é comum e levantando a suspeita de que a contaminação no voo anterior pode ter sido causada por outro meio de transmissão que não o aéreo. Tais achados parecem ser corroborados pelos dados apontados por Kampf et al (2020) acerca da baixa resistência do vírus fora do corpo humano, particularmente, em ambientes cuja temperatura é superior a $26^{\circ} \mathrm{C}$, limite de resistência do vírus, conforme também divulgado pela Associação Brasileira de Linfoma e Leucemia (MANCINI, 2020). Em decorrência do surto, desde 2003, a China aprimorou sua capacidade de resposta a epidemias, o que contribuiu para suas ações frente à COVID-19 (WU; MCGOOGAN, 2020).

Seguindo a tendência mundial, Wu e McGoogan (2020), a partir dos casos de COVID-19 ocorridos na China, tendo por referência a data de 11 fevereiro de 2020, produziram um relatório onde descrevem as frequências de ocorrência da infecção e de mortes por faixa etária. Os autores informam que as maiores taxas de infecção ocorrem na faixa de 30 a 79 anos (87\%), sendo a maioria de todos os casos (81\%) de grau leve. A maior Taxa de Letalidade (CFR) é encontrada acima de 79 anos de idade. A maior letalidade está relacionada a casos com pacientes em condições críticas ou em situações de comorbidades, especialmente, os acima 
de 79 anos. Ressaltam, ainda, que as condições críticas correspondem a apenas $5 \%$ dos casos, o que torna a morte um desfecho bastante modesto frente ao número de casos concretos.

Ferguson et al (2020), em um relatório emergencial do Imperial College COVID-19 Response Team (ICTR), a partir do estudo de casos recentes na China, Reino Unido e Itália, apresentaram um protocolo de combate à epidemia, com vistas a evitar uma pandemia, dirigido à Grã-Bretanha (GB) e EUA, mas, segundo eles, também, a qualquer país de alta renda, com a economia estável, capaz de suportar os inúmeros impactos econômicos a serem causados pelos procedimentos extremos, sendo necessário um estudo de viabilidade para uma adaptação às suas realidades particulares. Conforme deixam claro, já de início, o relatório não considerou as implicações éticas e econômicas das estratégias sugeridas, exceto para deixar claro que não se tratam de decisões fáceis e que podem, elas mesmas, acarretar enormes custos sociais, além dos econômicos, inclusive com impactos negativos sobre a saúde e o bem-estar social do curto ao longo prazo e que o foco de preocupação foi tão somente as questões técnicas relacionadas à responsividade dos sistemas de Saúde nos EUA e GB.

Nesse sentido, os autores (FERGUSON et al, 2020) postularam intervenções nãofarmacêuticas (INF), conforme Quadro 1, com duas possibilidades de ação, e suas subdivisões, que poderiam ser utilizadas de forma isolada ou conjunta, sendo a forma conjunta identificada como a de maior eficácia: (1) Supressão do contágio, por meio de ações que vão desde o isolamento social de casos confirmados ao fechamento de instituições educacionais e estabelecimentos comerciais, passando pela quarentena domiciliar de todos os cidadãos; (2) Mitigação do contágio, que representa a adoção de medidas de racionalização do uso dos sistemas de Saúde, privilegiando-se aqueles que mais necessitam do atendimento hospitalar, em detrimento dos casos menos graves e de menor risco à vida do paciente. 
Quadro 1 - Sumário das intervenções não-farmacêuticas (INF), considerando as taxas de redução do contato social em ambientes críticos e a concomitante aumento reflexo do contato em ambientes familiares e comunitários.

\begin{tabular}{|c|c|c|}
\hline \multicolumn{2}{|r|}{ POLÍTICA } & \multirow{2}{*}{$\begin{array}{l}\text { DESCRIÇÃo } \\
\text { Reclusão domiciliar dos casos sintomáticos por } 7 \\
\text { dias, reduzindo em } 75 \% \text { os contatos não } \\
\text { domésticos nesse período. Os contatos das famílias } \\
\text { permanecem inalterados. Supõe-se que } 70 \% \text { das } \\
\text { famílias cumpram a política }\end{array}$} \\
\hline IDCS & Isolamento domiciliar de casos sintomáticos & \\
\hline QDV & Quarentena domiciliar voluntária & $\begin{array}{l}\text { Após a identificação de um caso sintomático na } \\
\text { família, todos os membros da família permanecem } \\
\text { em casa por } 14 \text { dias. As taxas de contato das } \\
\text { famílias dobram durante esse período de } \\
\text { quarentena; os contatos na comunidade reduzem } \\
\text { em } 75 \% \text {. Suponha que } 50 \% \text { da família cumpra com } \\
\text { a política }\end{array}$ \\
\hline DSI & Distanciamento social de idosos (>70 anos) & $\begin{array}{l}\text { Redução dos contatos em } 50 \% \text { nos locais de } \\
\text { trabalho, aumento dos contatos da família em } 25 \% \\
\text { e redução de outros contatos em } 75 \% \text {. Assume-se } \\
75 \% \text { de obediência à política. }\end{array}$ \\
\hline DSG & Distanciamento social geral & $\begin{array}{l}\text { Redução das taxas de contato no local de trabalho } \\
\text { em } 25 \% \text {. Presume-se que as taxas de contato das } \\
\text { famílias aumentem } 25 \% \text {. Assume-se redução de } \\
\text { todo o convívio social em } 75 \% \text {. }\end{array}$ \\
\hline FIE & Fechamento de instituições educacionais & $\begin{array}{l}\text { Fechamento de todas as escolas e de } 75 \% \text { das } \\
\text { universidades. As taxas de contato das famílias dos } \\
\text { estudantes aumentam em } 50 \% \text { durante o } \\
\text { fechamento. Os contatos na comunidade } \\
\text { aumentam em } 25 \% \text { durante o fechamento. }\end{array}$ \\
\hline REI & Redução do impacto epidêmico & $\begin{array}{l}\text { Racionalização do uso de recursos farmacêutico- } \\
\text { médico-hospitalares conforme a gravidade dos } \\
\text { sintomas e do potencial risco à vida do paciente, } \\
\text { controlando as taxas de contágio e de mortalidade } \\
\text { e o impacto sobre os sistemas de Saúde, evitando- } \\
\text { se seu colapso, mas sem reduzir, diretamente, o } \\
\text { número total final de pessoas contaminadas, que } \\
\text { tenderão ao decréscimo, no médio prazo, por } \\
\text { imunização populacional espontânea indireta. }\end{array}$ \\
\hline
\end{tabular}

Fonte: Adaptado de Ferguson et al (2020, p. 6)

Quadro 2 - Conclusões gerais sobre a COVID-19.

- Indivíduos sintomáticos são, pelo menos, 50\% mais contagiosos que indivíduos assintomáticos;

- Na recuperação da infecção, presume-se que os indivíduos sejam imunes à reinfecção a curto prazo;

- Existe subavaliação da ordem de 40 a 50\% de infecções não identificadas, por serem assintomáticas ou possuírem sintomas leves não notificados;

- É provável que a mitigação não previna o colapso dos sistemas de Saúde por muito tempo, sendo necessário associar as medidas de supressão, concomitantemente, nos países capazes de suportar os impactos decorrentes;

- o fechamento de instituições educacionais é mais eficaz na supressão do contágio do que a quarentena domiciliar, e o bloqueio completo das estações de trabalho seria a medida mais eficaz, mas com um impacto preocupante sobre a economia; 


\begin{tabular}{|c|c|}
\hline- & $\begin{array}{l}\text { Em um contexto em que as relações interpessoais e os contatos foram drasticamente reduzidos pelas } \\
\text { intervenções implementadas (China), } 80 \% \text { das transmissões se deu no ambiente domiciliar, o que } \\
\text { coloca em xeque a eficácia plena da supressão social drástica; }\end{array}$ \\
\hline- & $\begin{array}{l}\text { A interrupção de reuniões de massa possui um impacto relativamente pequeno, pois o tempo de } \\
\text { contato nesses eventos é relativamente pequeno se comparado ao tempo em domicílios, nas escolas } \\
\text { ou nos locais de trabalho e em outros locais da comunidade, como bares e restaurantes; }\end{array}$ \\
\hline- & $\begin{array}{l}\text { Para se evitar um retorno da epidemia, após seu controle, seria necessário manter as políticas de } \\
\text { supressão e mitigação até a ampla disponibilização da vacina, o que demoraria } 18 \text { meses ou mais, ou } \\
\text { pelo menos intercalar a períodos constantes momentos e modos de supressão, sob vigilância restrita } \\
\text { das taxas epidemiológicas; }\end{array}$ \\
\hline- & $\begin{array}{l}\text { Medidas de supressão regionalizadas e contextualizadas são mais eficazes que medidas nacionais } \\
\text { uniformes, pois as taxas locais não são sincronizadas, especialmente, em países de grandes } \\
\text { proporções, e a racionalização da política implicará em menores impactos negativos, uma vez que a } \\
\text { paralizção das atividades seguirá tempos diferentes; }\end{array}$ \\
\hline- & $\begin{array}{l}\text { O distanciamento social de grupos de alto risco é eficaz na redução de resultados graves, embora } \\
\text { possa ter menor efeito na redução da transmissão populacional; }\end{array}$ \\
\hline- & $\begin{array}{l}\text { A extensão territorial e a idade populacional são duas variáveis centrais no cálculo da mortalidade e } \\
\text { da dispersão do vírus, assim, a epidemia atingirá um maior número de casos, com um pico mais } \\
\text { demorado nos EUA, por sua maior extensão territorial, do que na GB, onde o pico de óbitos será } \\
\text { maior, devido à sua menor área geográfica e maior média de idade populacional; }\end{array}$ \\
\hline- & $\begin{array}{l}\text { O atendimento em unidades de terapia intensiva (UTI) será necessário a, apenas, } 30 \% \text { das pessoas } \\
\text { hospitalizadas e, destes, } 50 \% \text { irão a óbito, assim como uma proporção não estimada de pacientes que } \\
\text { não estão na UTI, mas se incluem em grupos de risco, pela faixa etária ou por condições prévias de } \\
\text { saúde precária; }\end{array}$ \\
\hline- & $\begin{array}{l}\text { As taxas de mortalidade por infecção (IFR) variam conforme a idade e condições prévias de saúde do } \\
\text { paciente, sendo da ordem geral de } 0,9 \%, \quad \text { em média, para a GB e } \\
\text { EUA. }\end{array}$ \\
\hline
\end{tabular}

Fonte: Adaptado de Ferguson et al (2020).

As principais conclusões a que Ferguson et al (2020) chegaram estão nos Quadros 2 e 3. Os autores consideram que, por falta de alternativa, a medida de supressão, com a concomitante mitigação, parece ser a única opção ao surto do SARS-CoV-2, mas que, ainda conforme os autores, não podemos nos esquecer que a política sugerida no relatório está carregada de muitas incertezas, dada a complexidade do problema e o ineditismo das ações, e pode não surtir os efeitos desejados, bem como resultará um não avaliado impacto social e econômico profundo. Destacam, ainda, que é importante (e que, provavelmente, ocorrerá) uma mudança do comportamento populacional quanto aos fatores que podem desencadear surtos futuros semelhantes, ainda que as imposições governamentais não sejam mais necessárias e tenham sido suspensas. Para tanto, não é demais evocar o papel da Educação, em geral, e da Educação em Saúde, em particular, tanto domiciliar, quanto escolar e comunitária, o que exige a participação ativa do Estado em outro nível, de viés preventivo e não-flexneriano (PAGLIOSA; DA ROS, 2008; ALMEIDA FILHO, 2010; NUNES, 2010; MAMEDE 2016), no âmbito da Saúde Coletiva, em campanhas, programas e movimentos sociais perenes, a fim de se evitar as medidas extremas emergenciais intempestivas que têm caracterizado as 
ações governamentais ao longo da recente história sanitária, não apenas do Brasil, mas do mundo, o que pode ser ilustrado pela epidemia da Varíola, no Brasil, que deu origem à Revolta da Vacina, em 1904, e pela pandemia da Influenza em 1918, 1957, 1968 e 2009.

Quadro 3 - Estimativas atuais da gravidade dos casos e das Taxas de Mortalidade, por faixa etária, conforme Ferguson et al (2020, p. 5). As estimativas da Taxa de Mortalidade foram ajustadas para levar em conta uma taxa de ataque não uniforme, resultando em uma Taxa de Mortalidade Geral de 0,9\% (intervalo de confiança de $95 \%$ de $0,4 \%$ a $1,4 \%$ ). As estimativas de hospitalização também foram ajustadas dessa maneira e escalonadas para corresponder às taxas esperadas na faixa etária mais avançada (mais de 80 anos) para a GB e os EUA.

\begin{tabular}{|l|c|c|c|}
\hline $\begin{array}{l}\text { Age-group } \\
\text { (years) }\end{array}$ & $\begin{array}{c}\text { \% symptomatic cases } \\
\text { requiring hospitalisation }\end{array}$ & $\begin{array}{c}\text { \% hospitalised cases } \\
\text { requiring critical care }\end{array}$ & Infection Fatality Ratio \\
\hline 0 to 9 & $0.1 \%$ & $5.0 \%$ & $0.002 \%$ \\
\hline 10 to 19 & $0.3 \%$ & $5.0 \%$ & $0.006 \%$ \\
\hline 20 to 29 & $1.2 \%$ & $5.0 \%$ & $0.03 \%$ \\
\hline 30 to 39 & $3.2 \%$ & $5.0 \%$ & $0.08 \%$ \\
\hline 40 to 49 & $4.9 \%$ & $6.3 \%$ & $0.15 \%$ \\
\hline 50 to 59 & $10.2 \%$ & $12.2 \%$ & $0.60 \%$ \\
\hline 60 to 69 & $16.6 \%$ & $27.4 \%$ & $2.2 \%$ \\
\hline 70 to 79 & $24.3 \%$ & $43.2 \%$ & $5.1 \%$ \\
\hline $80+$ & $27.3 \%$ & $70.9 \%$ & $9.3 \%$ \\
\hline
\end{tabular}

Fonte: Ferguson et al (2020, p. 5).

Para Ioannidis (2020), epidemiologista e estatístico da Universidade de Stanford, a Taxa de Letalidade (CFR) ${ }^{\dagger}$ do COVID-19 varia de 0,05 a 1\%, acometendo, predominantemente, indivíduos já com baixa expectativa de vida, diferentemente e não mais preocupante que o Influenza ou outras afecções respiratórias e não justificando as medidas extremas já adotadas. Afirma, ainda, que convivemos há décadas com o SARS-CoV, que muitos infectados sequer chegam a ser notificados e que a detecção de um vírus no post mortem não implica, necessariamente, que este vírus tenha sido a causa-morte primária, devendo-se ter parcimônia com tais constatações. Para suportar suas conclusões, realiza uma análise das taxas e da situação identificadas à bordo do Diamond Princess, um navio de cruzeiro, cujos passageiros foram infectados pela COVID-19, e as extrapola para a população dos EUA, realizando as devidas adaptações. Com base nisso, propugna que os resultados das medidas

\footnotetext{
$\dagger$ IFR, ou Taxa de Mortalidade, difere de CFR, ou Taxa de Letalidade, por considerar o número de mortes por casos concretos detectados e casos suspeitos, ou seja, todos sob risco de morrer, enquanto a CFR considera apenas as mortes por casos concretos detectados.
} 
de lockdown podem ser sabotados pela maior convivência familiar, o que criaria outra via de contágio, talvez, mais eficiente que outros espaços sociais bloqueados. Ferguson et al (2020) procuram relativizar tais sabotagens involuntárias dos resultados em suas medidas nãofarmacêuticas, mas reconhecem que uma experiência de sucesso do lockdown, vivenciada na China, tornou as relações domiciliares responsáveis por $80 \%$ das transmissões.

Ainda conforme Ioannidis (2020), no que é corroborado por Patton (2020), a adoção das medidas extremas em curso pode representar extensa crise social e econômica, além de sérios problemas de saúde mental, que podem provocar ansiedades, depressão e, mesmo, acirrar desavenças, elevar níveis de agressividade e tornar a convivência social em reclusão insustentável. A este respeito, Freud (1996/1929) já alertava para as possibilidades de elevação da agressividade interpessoal quando as exigências normativas extrapolam a capacidade de resposta do indivíduo e que é ingenuidade achar que estamos aptos a responder pronta, pacífica e eficientemente a todas as exigências que frustram nossas expectativas de felicidade e prazer, seja no âmbito pessoal, seja no social. Ainda para Freud, nossa felicidade pessoal é sempre relativizada pelas possibilidades sociais de sua materialização e uma das formas de compensação pelas frustrações diárias a um modelo de felicidade egoísta é, justamente, o estabelecimento dos laços sociais que movimentam o processo civilizatório, em busca da felicidade coletiva. Uma vez que as medidas de lockdown privam o indivíduo dessas possibilidades, indo na contramão do movimento civilizatório, a frustração acumulada e o confinamento têm grande potencial para elevar os níveis de agressividade social, elevando, inclusive, a violência doméstica e, no extremo, a violência nas ruas, por vigilantes que se autoimponham a tarefa de evitar a "sabotagem" do bloqueio. Brincadeiras e casos isolados, nesse sentido, já têm circulado nas redes sociais e experiências de confinamento, em navios, a trabalho, ou mesmo nos programas televisivos do gênero reality show são exemplos ilustrativos dessas premissas.

\section{O CASO BRASIL}

Em 11 de março de 2020, a OMS declarou a situação com o SARS-CoV-2, uma pandemia. No Brasil, o Ministério da Saúde e seus órgãos associados implementaram uma política restritiva radical de supressão, quase imediatamente à divulgação. $O$ Plano de Contingência do Ministério da Saúde prevê que "O Brasil adota a ferramenta de classificação de emergência 
em três níveis [Alerta, Perigo Iminente e Emergência Pública], seguindo a mesma linha utilizada globalmente na preparação e resposta em todo o mundo..." (BRASIL, 2020a, p. 4), e afirma, de forma ainda bastante coerente com a situação atual:

...até o momento, fatos e conhecimentos sobre o novo coronavírus (COVID-19) disponíveis são limitados. Há muitas incertezas no modo exato de transmissão e os possíveis reservatórios. As taxas de letalidade, mortalidade e transmissibilidade não são definitivas e estão subestimadas ou superestimadas. As evidências epidemiológicas e clínicas ainda estão sendo descrita e a história natural desta doença está sendo construída. As informações cruciais para apoiar avaliação dos fatores mencionados, como infectividade, transmissibilidade, taxa de complicações, letalidade, mortalidade, serão gradualmente disponibilizadas...(BRASIL, 2020a, p. 5).

As diretrizes para avaliação de riscos, adotadas pelo Plano de Contingência, para enfrentar, inclusive, outras situações semelhantes à pandemia do COVID-19, são:

[1] Transmissibilidade da doença, como seu modo de transmissão, eficácia da transmissão entre reservatórios para humanos ou humano para humano, capacidade de sustentar o nível da comunidade e surtos;

[2] Propagação geográfica do novo coronavírus (COVID-19) entre humanos, animais, como a distribuição global das áreas afetadas, o volume de comércio e viagens entre as áreas afetadas e outras unidades federadas;

[3] Gravidade clínica da doença, como complicações graves, internações e mortes;

[4] Vulnerabilidade da população, incluindo imunidade pré-existente, grupos-alvo com maiores taxas de ataque ou maior risco de graves doenças;

[5] Disponibilidade de medidas preventivas, como vacinas e possíveis tratamentos; e

[6] Recomendações da Organização Mundial da Saúde e evidências científicas publicadas em revistas científicas (BRASIL, 2020a, p. 5)

A partir daí, assumindo sua parcela de responsabilidade com a possibilidade de "erro pelo excesso" (BRASIL, 2020a, p. 4) em decorrência da falta de informação, o Plano define os níveis de resposta (Alerta, Perigo Iminente e Emergência Pública-Contenção e Mitigação) e os apresenta com seus indicadores (precários) junto ao que pode ser considerada uma série de objetivos a serem alcançados, subdivididos conforme as medidas de resposta (Vigilância, Suporte laboratorial, Medidas de controle de infecção, Assistência, Assistência farmacêutica, Vigilância Sanitária em pontos de entrada, Comunicação de risco e Gestão), e define a estrutura de comando, ou seja, os stakeholders envolvidos com sua execução. Contudo, o Plano não explicita qualquer processo ou estratégia operacional concreta para sua 
implantação e implementação e, tampouco, expressa suas preocupações com a necessária adaptação de contexto das orientações emanadas da Organização Mundial de Saúde (OMS) e com métodos de monitoramento e avaliação dos resultados, etapas necessárias ao planejamento de uma política pública (MAMEDE, 2016; 2019). Além disso, as medidas de supressão, amplamente, utilizadas na prática, durante a presente crise, em atendimento às premissas do Imperial College COVID-19 Response Team (FERGUSON et al, 2020), não se encontram presentes no Plano de Contingência brasileiro e, aparentemente, não foram alvo de uma análise criteriosa por parte da equipe responsável por sua implantação no Brasil.

Figura 1: Umidade média anual das cidades brasileiras comparada a outras cidades no mundo, demonstrando a variabilidade das condições brasileiras, em decorrência de seu extenso território.

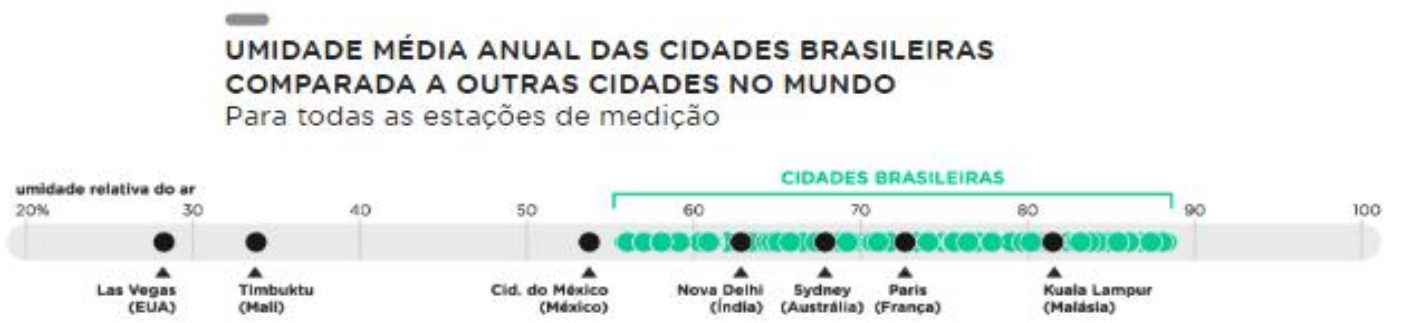

Fonte: Jornal Nexo, a partir de dados do Banco de Dados Meteorológicos para Ensino e Pesquisa, do Instituto Nacional de Meteorologia e do Centro de Gerenciamento de Emergências (https://www.nexojornal.com.br/grafico/2017/09/25/Como-\%C3\%A9-a-umidade-do-ar-nascapitais-ao-longo-do-ano)

O Brasil é um país de dimensões continentais, com uma economia errática e frágil, costumes e densidades demográficas tão variados quanto suas características geográficas, população relativamente jovem e temperaturas predominantemente quentes, possuindo amplitudes térmicas, climas e umidades relativas tão diversos quanto suas diferentes regiões, o que lhe confere características bem particulares e distintas daquelas encontradas em países de pequena extensão, como a GB e outros países europeus, ou localizados no hemisfério Norte, como os EUA (Figuras 1, 2, 3 e 4). 
Figura 2: Condição ambiental com ponto de orvalho acima de $18^{\circ} \mathrm{C}$, frente à incidência de energia solar diária em Wuhan, Nova Iorque, Roma, Madrid, Fortaleza, São Paulo, Rio de Janeiro e Brasília., com base em uma análise de relatórios estatísticos para 01/01/1980 a 31/12/2016, baseadas no modelo MERRA-2.
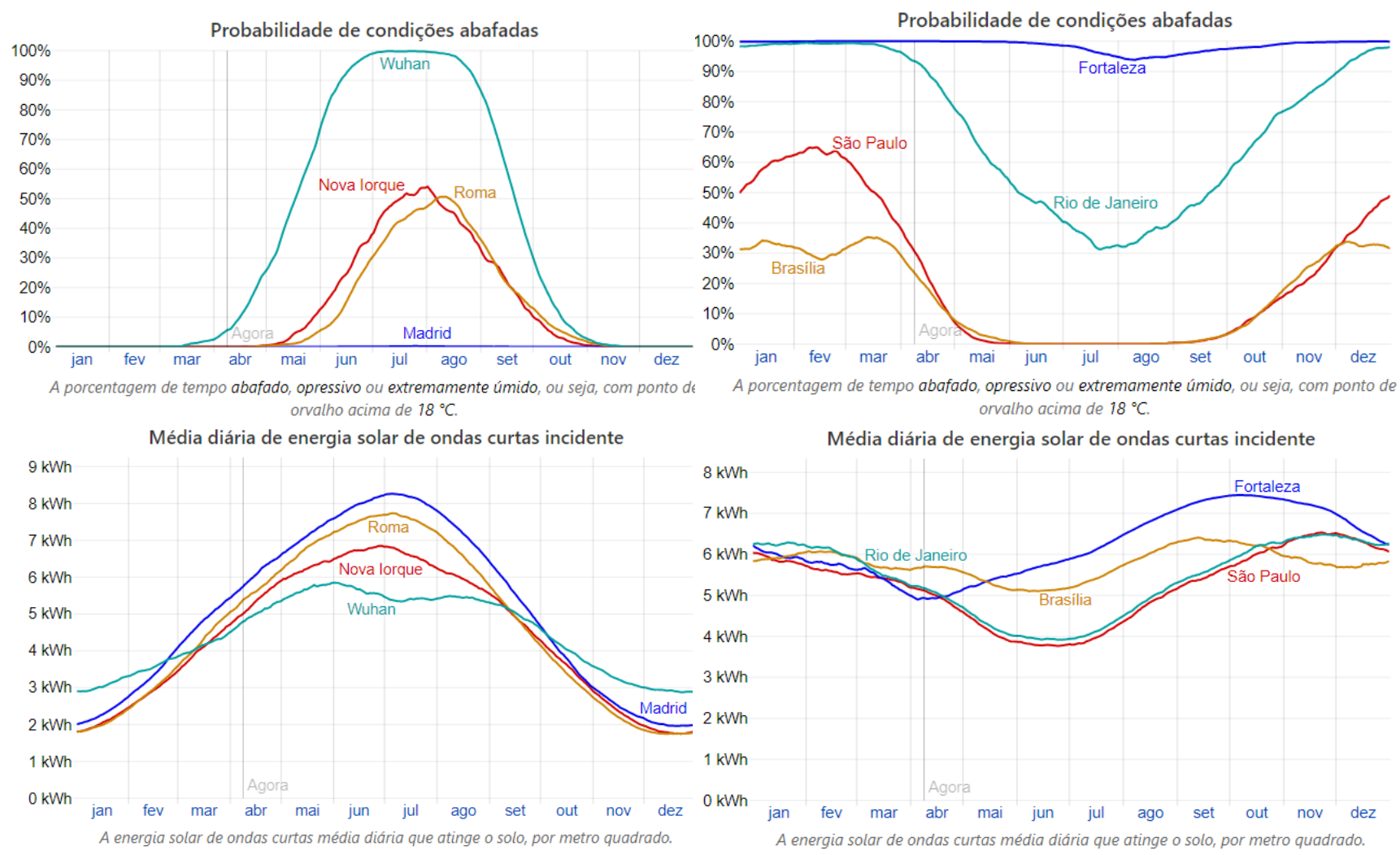

Fonte: Produção própria, a partir do software online Weader Spark- https://pt.weatherspark.com/.

Ademais, nosso país possui temperaturas que oscilam, de um extremo a outro do território, entre menos de $0^{\circ} \mathrm{C}$ (alcançando $11^{\circ} \mathrm{C}$ negativos, em Xanxerê, Santa Catarina, em 20 de julho de 1953 ) e mais de $35^{\circ} \mathrm{C}$ (chegando a incríveis $44,7^{\circ} \mathrm{C}$ em Bom Jesus do Piauí, no Piauí, em 21 de novembro de 2005, e à inacreditável sensação térmica de $81^{\circ} \mathrm{C}$, em Antonina, no Paraná em finais de 2018), possuindo como médias máximas de temperatura anual algo em torno de $30,4^{\circ} \mathrm{C}$, médias mínimas em torno de $24,6^{\circ} \mathrm{C}$, média geral de, aproximadamente, $20^{\circ} \mathrm{C}$ (RAMOS et al, 2018; CRUZ, 2020). Isso contrasta, grandemente, com países europeus como Itália, cujas temperaturas são bem mais amenas que as brasileiras, permanecendo 4 meses com temperatura máxima média em torno de $15^{\circ} \mathrm{C}$, alcançado uma média de $28^{\circ} \mathrm{C}$ no período mais quente do ano e uma média anual próxima a $18^{\circ} \mathrm{C}$. Tal realidade não é muito diferente quando analisamos a maior parte das regiões da Inglaterra ou mesmo para os Estados Unidos 
da América (EUA) e para a China, onde, em Wuhan, se iniciou o surto do SARS-CoV-2. Considerando todos esses cenários (Figuras 1, 2, 3 e 4), as condições climáticas brasileiras parecem ser bem menos favoráveis à disseminação do vírus do que as condições do Norte americano, da China e dos países europeus.

Figura 3: Umidade média anual em diferentes regiões do Brasil, entre 1961 e 2016. Cada ponto é uma estação de medição.

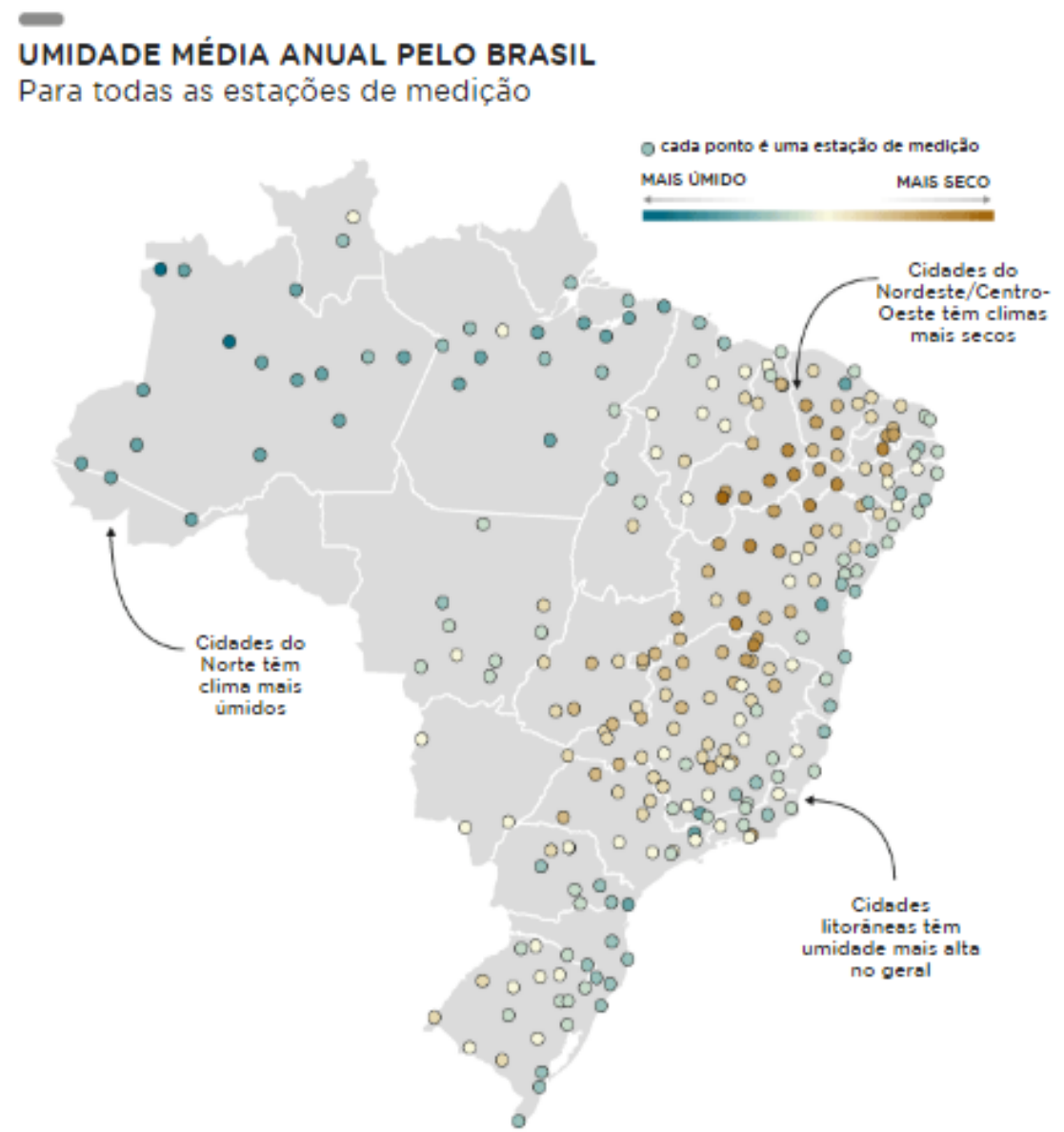

Fonte: Jornal Nexo, a partir de dados do Banco de Dados Meteorológicos para Ensino e Pesquisa, do Instituto Nacional de Meteorologia e do Centro de Gerenciamento de Emergências (https://www.nexojornal.com.br/grafico/2017/09/25/Como-\%C3\%A9-aumidade-do-ar-nas-capitais-ao-longo-do-ano)

A despeito das preocupações com a aparente maior letalidade da COVID-19 em relação à gripe comum, o vírus sobrevive 28 dias em uma gota, a uma temperatura inferior a $10 \mathrm{oC}$, mas não mais que um dia se a temperatura alcançar 30oC (DOMINGUÉZ, 2020). Para a Associação Brasileira de Linfoma e Leucemia (MANCINI, 2020), o coronavírus não resiste 
muito tempo a uma temperatura igual ou superior a $260 \mathrm{C}$ fora do corpo humano, sendo as temperaturas no Brasil desfavoráveis a ele. Tais constatações indicam ser pouco provável a possibilidade de contaminação aérea, particularmente, no Brasil, o que vai ao encontro do que postularam Cheng et al (2007) para o SARS-CoV, especialmente, em um ambiente seco ou quente, no qual um perdigoto seja lançado ao ar e não ocorra seu contato quase imediato com a mucosa de um hospedeiro. Um estudo apresentado por Kampf et al (2020), no qual realizam um levantamento da bibliografia e evidenciam testes com várias cepas do coronavírus, corrobora essas informações. Conforme esses autores, entre $22^{\circ} \mathrm{C}$ e $25^{\circ} \mathrm{C}$, em materiais plásticos, o vírus resiste, aproximadamente, até cinco dias. A uma temperatura de $21^{\circ} \mathrm{C}$, o vírus resiste, no alumínio, até oito horas e, em PVC ou cerâmica, persiste até cinco dias. À temperatura ambiente, em condições laboratoriais, o vírus poderá sobreviver, aproximadamente, de quatro a cinco dias no papel, quatro dias no vidro e madeira e cinco dias no metal. Além disso, foi relatado o grau de resistência do vírus a substâncias como álcool, formaldeído, glutaraldeído, iodo, hipoclorito de sódio e peróxido de hidrogênio, sendo o etanol com concentrações entre 62 e 71\%, e o hipoclorito de sódio a 0,1\% as substâncias com melhor eficiência em exposições de até 1 min. Também a umidade relativa do ambiente demonstrou ser um fator diretamente proporcional à taxa de sobrevivência do vírus. Tal estudo além de dar indicações sobre as formas de desinfecção de superfícies, a fim de evitarse a disseminação da infeção pelo contato direto com objetos contaminados, possibilita uma noção aproximada da resistência ambiental do coronavírus e fornece orientações sobre a dinâmica de transmissão do SARS-CoV-2. 
Figura 4: Comparação das temperaturas médias máximas e mínimas e dos graus acumulados-ano, das cidades de Roma, Madrid, Wuhan, Nova Iorque, São Paulo, Rio de Janeiro, Brasília e Fortaleza, com base em uma análise de relatórios estatísticos para 01/01/1980 a 31/12/2016, baseadas no modelo aranan a

Temperaturas máximas e mínimas médias
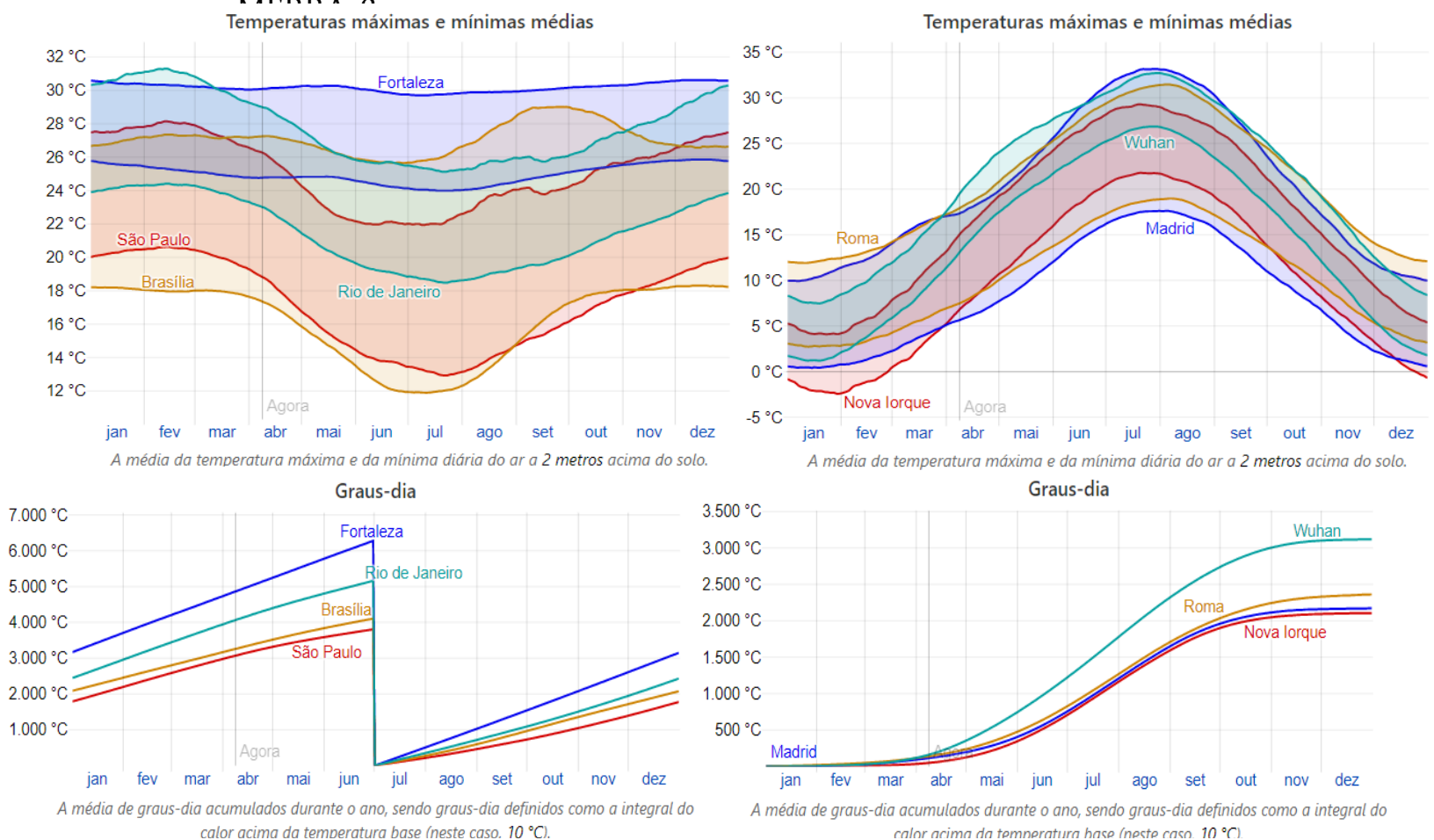
calor acima da temperatura base (neste caso, $10^{\circ} \mathrm{C}$. calar acima da tomnoratura hase (noste case $\left.10^{\circ} \mathrm{C}\right)$

Fonte: Produção própria a partir do software online Weather Spark- https://pt.weatherspark.com/.

Uma avaliação, meramente, técnica e quantitativa dos dados apresentados por Ferguson et al (2020), sintetizados na Figura 5, leva-nos a chancelar o transplante da proposta para o cenário nacional, como tem sido realizado. No entanto, à luz das conclusões apontadas pelos próprios autores e diante de uma análise mais acurada do contexto brasileiro, frente aos dados trazidos por Cheng et al (2007) e Kampf et al (2020) e ao alerta de que o relatório apresentado pelo Imperial College COVID-19 Response Team não realizou uma necessária avaliação dos impactos econômicos, sociais e éticos de implementação do seu plano de contenção, tal chancela é colocada em xeque e suscita dúvidas quanto à sua adequação e eficiência no Brasil, caso não sejam realizadas as devidas adaptações, a partir de indicadores contextuais, como convém à transferência de uma política pública entre diferentes cenários, qualquer que seja ela (MAMEDE, 2019). Se considerarmos as diretrizes do Plano de Contingência brasileiro (BRASIL, 2020a) e as confrontarmos com as conclusões emanadas do ICTR (FERGUSON et al, 2020), teremos uma dimensão das variáveis de contexto necessárias à reavaliação da viabilidade da política implantada. 
Figura 5: Cenários de estratégia de mitigação para GB mostrando requisitos de leito de cuidados intensivos (UTI). A linha preta mostra a epidemia não mitigada. A linha verde mostra uma estratégia de mitigação incorporando o fechamento de escolas e universidades; a linha laranja mostra o isolamento do caso; a linha amarela mostra o isolamento dos casos e a quarentena das famílias; e a linha azul mostra o isolamento dos casos, a quarentena doméstica e o distanciamento social das pessoas com mais de 70 anos. O sombreamento azul mostra o período de três meses em que essas intervenções devem permanecer no local.

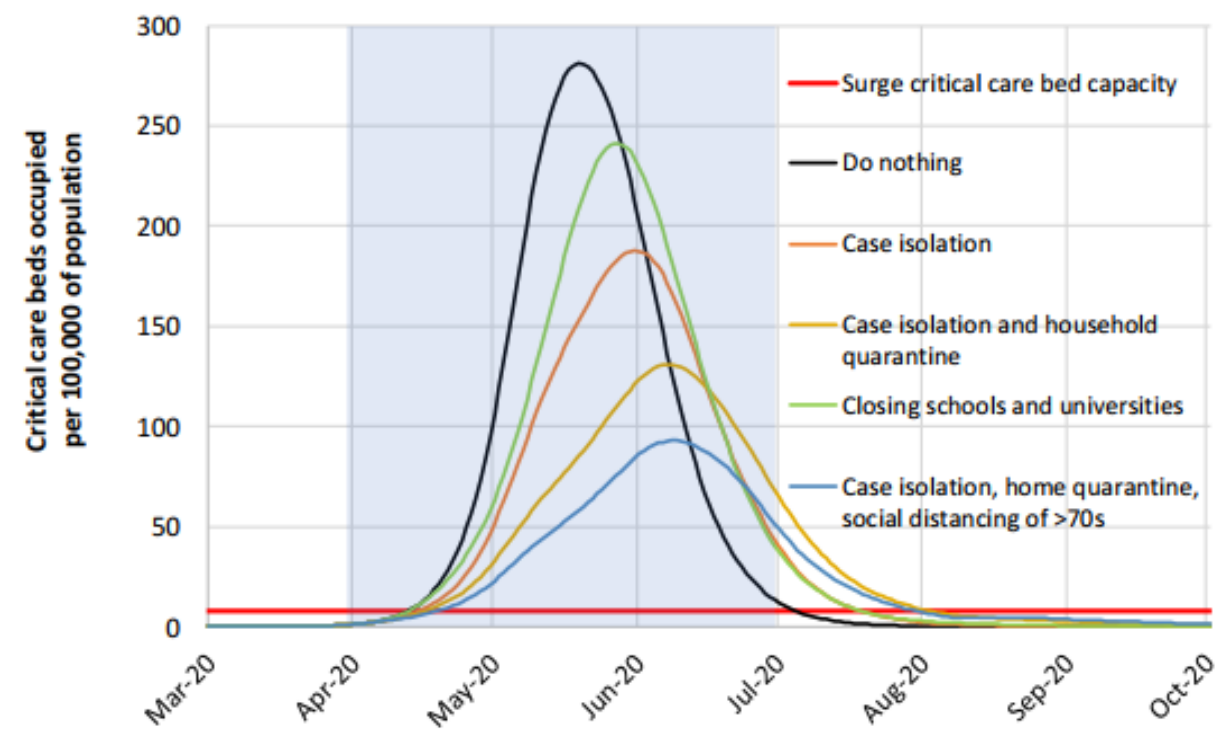

Fonte: Ferguson et al (2020, p. 8).

Nesse sentido, a primeira diretriz do Plano Nacional de Contingência Nacional para o COVID-19 (BRASIL, 2020a) propõe a análise da transmissibilidade e da capacidade de sustento às medidas de combate à crise. No entanto, parece não ter sido aplicada em sua plenitude. Ao considerarmos a realidade contextual do Brasil, podemos inferir que as formas e amplitude das transmissões por aqui podem não ter as mesmas características encontradas no China, Itália e Reino Unido, países de referência para os estudos de caso empreendidos na elaboração do ICTR e que contêm os princípios das políticas de lockdown horizontal adotadas pelo mundo (FERGUSON et al, 2020). Tal constatação nos encaminha para outra: o isolamento radical pode não ser a melhor solução, especialmente, para o Brasil. Ao cruzarmos essa hipótese com a orientação de Ferguson et al (2020) sobre a potencial maior eficiência de regionalização contextual das medidas dentro do próprio país que as adotar, inferimos uma outra: aparentemente, o COE-COVID-19, não empreendeu a adequada avaliação da política para sua implantação contextualizada na realidade do país, apenas reproduzindo orientações 
emanadas de órgãos internacionais, como a OMS, a partir de realidades díspares encontradas no exterior, uma determinação presente na última diretriz do Plano Nacional, em resposta ao pressuposto de "errar pelo excesso". Nesse sentido, a capacidade de sustento às medidas de combate não foi também considerada, adequadamente, o que indica a possibilidade de necessidade de interrupção das ações de forma precoce e em um ponto aquém do que seria esperado em termos de controle da transmissibilidade, comprometendo, sobremaneira, a primeira diretriz do Plano.

É fato que evidências científicas robustas e tempestivas sobre o COVID-19 não estão disponíveis em quantidade e qualidade necessárias ao enfrentamento da crise e atendimento de parte da última diretriz do Plano Nacional (a consulta a "evidências científicas publicadas em revistas científicas") e que, como o próprio Plano adverte, informações cruciais para sua superação ainda estão sendo produzidas, para que decisões sejam tomadas. No entanto, alguma informação já existe, como o próprio ICTR ou o relatório apresentado por Wu e McGoogan (2020) ou mesmo as orientações emanadas da OMS (WHO, 2020), e sua adequada análise, frente às variáveis de contexto brasileiras, poderia ter orientado ações com perfil cirúrgico, em um lockdown vertical, parcimonioso e regionalmente contextualizado. A ausência de uma análise acurada das proposições gerais emanadas da OMS e do ICTR, produziram uma situação insustentável, não apenas no Brasil, que possui as condições mais favoráveis para uma ação mais amena, mas pelo mundo. Ainda que assumamos a máxima de que a "economia se recupera, vidas não", precisamos ter em mente que saúde não é um ente isolado da economia (consideremos o conceito ampliado de saúde da própria OMS, na equação) e que uma crise econômica da magnitude que se nos avizinha, além das questões éticas envolvidas, poderá gerar mais males para a saúde que o próprio COVID-19, algo que não se encerrará no presente, conforme já alertaram Wu e McGoogan (2020).

Dessa forma, as diretrizes do MS, presentes no Plano Nacional, e que versam sobre a propagação geográfica, gravidade clínica e vulnerabilidade da população ao COVID-19, deveriam ser relativizadas pelas características geográficas, demográficas e climatológicas presentes no Brasil, assim como pelas conclusões apresentadas no ICTR por Ferguson et al (2020) e por dados epidemiológicos e microbiológicos do SARS-CoV, discutidas por Cheng et al (2007), Kampf et al (2020) e Wu e McGoogan(2020), entre outros, e que nos obriga ao alerta sobre a necessária contextualização das medidas propostas (Quadro 1), inclusive, com uma parcimônia e reserva não aplicadas pelo MS, uma vez que algumas das medidas acabaram 
sendo aplicadas de forma mais radical do que a vislumbrada pelo ICTR. A exemplo temos o caso de fechamento precoce de $100 \%$ das universidades, no Brasil, quando foi identificado pelo ICTR um ideal de apenas 75\%. Pela falta de análise adequada e suficiente da situação frente aos dados disponíveis, a premissa de que a gravidade do problema é maior do que realmente deveria ser, em território nacional, foi assumida como valor de verdade inalienável e orientou a importação radical de uma política contextualizada em outras realidades.

O status pandêmico do SARS-CoV-2 foi estabelecido, basicamente, tendo por dados os casos ocorridos em países com caraterísticas muito diferentes das encontradas no Brasil. Para se ter uma ideia, os líderes mundiais em casos confirmados, à época (e, ainda hoje, com algumas diferenças de posição entre eles), eram China (80.955), Itália (10.149), Iran (8.042), França (1.774), Espanha (1.639), Alemanha (1.296), EUA (696) . Os demais países estavam (e, ainda estão) todos muito abaixo desses líderes, os casos no Brasil representando menos que $5 \%$ dos casos do sétimo colocado (WHO, 2020c,d), valores que necessitam ser relativizados pelo quantitativo populacional, densidade demográfica e condições climáticas, entre outras. Eduardo Massad, epidemiologista especialista em modelos matemáticos para estimar o ônus de doenças infectocontagiosas, da Fundação Getúlio Vargas, em entrevista para o MedScape (TARANTINO, 2020), afirma que as preocupações com a gravidade do COVID-19 podem estar superestimadas, em detrimento de outros problemas de Saúde do pais, particularmente se recordarmos que, em 2009, a OMS decretou pandemia do H1N1 e, alguns anos depois, uma epidemia do Zica e ambas situações, apesar do medo e do comportamento estereotipado gerados, arrefeceram, indicando precipitação das declarações e procedimentos. É certo que o Brasil não poderia ficar de fora de um acordo sanitário com o restante do mundo, a fim de combater a possibilidade de alastramento da contaminação, sob o risco de ser responsabilizado por negligência e sofrer toda sorte de sanção política, econômica e comercial por parte de seus parceiros comerciais e organismos internacionais de controle. No entanto, o modelo adotado, talvez, por uma falha no processo de transferência de uma política pensada para um contexto tão diferente ao do nosso país, já tem mostrado seus impactos negativos. o primeiro deles ou, pelo menos, o mais aparente de forma imediata, se deu no plano econômico: já no terceiro mês do ano, as contas públicas preveem um déficit de

\footnotetext{
¥ Contra China (81.116), Itália (27.980), Iran (14.991), Espanha (9.191), França (6.573), Alemanha (6.012), EUA (3.503), Brasil (234), em 17/03/2020, momento em que a quarentena se tornou compulsória no Brasil²3.
} 
mais de 124 bilhões de Reais para o ano de $2020^{\S}$, sendo declarado Estado de Calamidade Públicall, diante do compromisso financeiro assumido com a manutenção do plano de contenção do coronavírus (BRASIL, 2020c), o que encaminhará cortes orçamentários, reduções salariais e precarização de serviços ofertados pelo Estado ao cidadão, inclusive, na Saúde, uma vez que questões econômicas não estão desvinculadas de outras questões de ordem social, havendo implicações mútuas, na perspectiva de uma visão sistêmica de mundo (PATTON, 2020).

Tal consequência não se mostra, necessariamente, uma surpresa e poderia ter sido amenizada, caso a equipe responsável pela implantação e implementação da política de combate ao COVID-19 tivesse seguido mais de perto algumas das orientações constantes no documento apresentado por Ferguson et al (2020) e que contém os princípios dos protocolos adotados ao redor do mundo. A primeira e, talvez, a mais notória delas é justamente o alerta sobre a inexistência de avaliação do impacto econômico da política e as reservas existentes quanto à sua eficácia e aplicação em países com economias frágeis e instáveis, como a do Brasil. Isso se torna, ainda, mais preocupante quando nos atentamos para outra recomendação constante no relatório: as medidas de mitigação e supressão propostas não se encerram em poucos dias, ao contrário, necessitam se estender por, pelo menos 5 meses, com um possível relaxamento temporário e dependente das condições objetivas da pandemia, para posterior retomada das medidas de restrição social por um total de, pelo menos, 12 a 18 meses, até que a vacina seja amplamente disponibilizada para a população, sob o risco de que a pandemia tome novo fôlego e retorne a patamares próximos aos que possuía no início dos procedimentos. Diante das declarações atuais, materializadas no Decreto Legislativo no ${ }^{\circ}$, de 2020 (BRASIL, 2020c), parece óbvio que o Brasil não será capaz de suportar (e nem precisa), economicamente, tal estresse e terá despendido recursos que, além de não surtirem os efeito desejados, terão sido gastos em vão e sua falta pesará sobre outros setores da sociedade, fracionando e camuflando em diversas áreas, sobretudo da Saúde e nos investimentos sociais, os males que estariam, teoricamente, presentes na ameaça de epidemia a ser contida. Aqui, é importante dar destaque ao "teoricamente", pois é algo que se conecta, diretamente, com outras conclusões a que chegaram Ferguson et al (2020), as quais, em associação com as características geográficas, demográficas e climatológicas do Brasil e outras evidências, como

\footnotetext{
$\S$ https://www12.senado.leg.br/noticias/especiais/especial-cidadania/defesa-civil/situacao-de-emergencia-e-estado-de-calamidade-publica $\| \underline{\text { https://g1.globo.com/politica/noticia/2020/03/20/coronavirus-senado-aprova-decreto-que-reconhece-estado-de-calamidade-publica.ghtml }}$
} 
as trazidas por Cheng et al (2007), Kampf et al (2020), Ioannidis (2020) e Wu e McGoogan (2020), além da carência de evidências pacíficas e a profusão de informações truncadas, como aponta Patton (2020), podem relativizar a situação e parecem não ter sido consideradas na determinação da gravidade do problema. Como alerta Patton (2020) e demonstra Ioannidis (2020), existe uma necessidade premente de estudos sistemáticos estratificados para se determinar com maior precisão as taxas de infecção, o que implica uma necessária contextualização das análises, devendo ser esse o próximo passo de amadurecimento da crise.

\section{PANDEMIA OU INFODEMIA?}

Aparentemente, contribui para o excessivo rigor no julgamento da situação no Brasil, além da carência de informações científicas tempestivas e sedimentadas sobre a COVID-19, a profusão de informações desencontradas ou superestimadas, sem dados confiáveis, nas mídias e nos próprios órgãos estatais responsáveis pelo controle da crise (IOANNIDIS, 2020; PATTON, 2020), e a premissa de que o erro pelo excesso é algo, necessariamente, mais benéfico que o erro pela falta (BRASIL, 2020a), independentemente de suas iatrogenias poderem ser mais nefastas no longo prazo, pois estas não serão percebidas como consequência daquelas e a elas serão atribuídas, propositada ou inadvertidamente, outras causas.

Ainda que as iatrogenias de longo prazo possam ser, no presente, contestadas como possíveis, estamos já vivenciando iatrogenias mais imediatas: alimentos e outros produtos de primeira necessidade, inclusive, para hospitais, têm sumido das prateleiras; mercadorias têm sido hiperinflacionadas; medicamentos, como a Cloroquina, têm se esgotado por sua mera alusão (CHENG et al, 2007) como alcalinizante endossômico e potencial, não confirmado ", de combate ao vírus, o que impacta, diretamente, pacientes que deles necessitam para sua própria sobrevivência contra males que nenhuma relação possuem com a SARS-CoV-2; outros medicamentos, como os anti-inflamatórios não-esteroidais, foram demonizados, sem evidências robustas o suficiente para tal, e depois ressurgiram como potenciais amenizadores das afecções pulmonares secundárias aos processos infamatórios e de coagulação sistêmica

\footnotetext{
Il A despeito da posterior liberação da Cloroquina e da Hidroxicloroquina (com muitas reservas) pelo Ministério da Saúde (BRASIL, 2020d).
} 
provocadas pela COVID-19; mitos prejudiciais ao combate do próprio coronavírus, como o descrédito no teor alcóolico do álcool-gel e em sua eficácia e a ingesta de chás quentes, por ter se tornado do conhecimento público a baixa resistência do vírus ao calor (KAMPF et al, 2020) têm abundado; qualificação de recursos humanos no setor público e contratação de novos servidores via concurso têm sido suspensas ${ }^{* *}$; o comprometimento do período escolar a níveis que podem ser difíceis de recuperar; a iminente falência de micro e pequenas empresas, por sua impossibilidade em absorver os impactos financeiros negativos da medida de DSG, inclusive, em taxas superiores às recomendadas (Quadro 1) e as altas taxas de desemprego que se instalarão; proposta de redução salarial de servidores públicos em nome da contenção de gastos do Estado e a redução salarial já imposta para empregados privados em regime de homework ou afastados; problemas de saúde mental, com o consequente aumento da agressividade social, contra si e terceiros; entre outros efeitos colaterais que poderiam ser citados e estão, amplamente, descritos nas mídias sociais, dentre eles, a proliferação da desinformação, frente à carência de dados científicos em quantidade e qualidade suficientes à demanda emergente, o que nos torna reféns de fontes menos confiáveis de informação e mais sujeitas aos interesses particulares, que atuam na contramão do ethos mertoniano (MERTON, 1968) e encaminham ações excessivas de resposta, em nome do medo.

Segundo Taylor (2019), estamos vivendo uma fase "infodêmica", o que significa dizer que as redes sociais tendem a interferir na percepção que as pessoas podem ter sobre as questões sociais, produzindo uma avaliação exagerada do problema e uma disseminação de ideias pouco condizentes com a realidade ou com uma aproximação distorcida em relação a ela, o que redunda em comportamentos erráticos e destituídos de uma racionalidade fundamentada em fatos concretos. Informações fantasiosas e conspiracionistas tendem a alistar comportamentos estereotipados, pois dialogam, diretamente, com o sistema de crenças reducionistas acerca da realidade. Conforme Kappes et al (2018), em um estudo sobre como a incerteza afeta nosso comportamento, por meio de um experimento onde uma "gripe africana" fictícia foi utilizada para avaliar o comportamento das pessoas em relação a decisões que poderiam colocar em risco a vida de outras pessoas, o pânico não é imediato, mas surge quando as pessoas identificam que estão, de fato, sujeitas ao risco que atribuíam, somente,

\footnotetext{
*** O concurso da Polícia Civil do Distrito Federal e da Prefeitura de Goiânia, inclusive, para a Secretaria de Saúde, estão entre os primeiros a serem suspensos, sem previsão de retomada, apesar da grande demanda social existente por servidores.
} 
aos outros, a partir de um fator estressor, que rompe a fase de negação, como, por exemplo, uma superexposição midiática ao tema. Assim, começamos a adotar atitudes valorativas em relação aos resultados estatísticos oficiais, desconfiando deles, identificando a nós e nossos entes queridos com as vítimas, e os cenários projetados tornam-se pessimistas. Como, naturalmente, temos dificuldade para aceitar soluções simples para problemas, aparentemente, complexos, frente às desconfianças em relação às informações oficiais, começamos a balizar nosso comportamento no padrão de comportamento concreto ou imaginado de outras pessoas, condicionando nossas ações no chamado "efeito manada", que tem alcançado todos os estratos sociais e profissionais, incluindo os tomadores de decisão no nível político.

\section{CONSIDERAÇÕES FINAIS}

Partindo dos pressupostos apontados até então, mostra-se temerária a implantação mecânica da política de contenção da COVID-19 em contextos, cujas realidades geográficas, sociais, culturais e econômicas divirjam sobremaneira das realidades para as quais as estratégias foram pensadas, sem sua devida adaptação, por meio de uma análise contextual da implantação. Ainda que tenhamos como contexto mais amplo a própria realidade mundial, em uma crise, globalmente, interconectada, não podemos negligenciar fatos e evidências de contextos mais locais, sendo esse um papel central da comunidade internacional de avaliadores.

Diante da situação extrema que o mundo está vivendo, tem transbordado na mídia a opinião de especialistas, transformando os veículos midiáticos, talvez, na maior fonte de informações sobre o COVID-19, antes mesmo de sua publicação nos veículos científicos, uma vez que tais veículos costumam ser morosos, em razão da necessidade (legítima) que a Ciência possui de se precaver contra informações truncadas e falaciosas, por meio do peer review. Nesse sentido, temos, ainda, opiniões de leigos, que arrogam a competência para avaliar, tecnicamente, a situação, disseminando informações desencontradas daquelas emitidas por profissionais sérios e comprometidos que, apesar disso, destoam diametralmente entre si sobre a melhor direção a se tomar, em uma controvérsia viva, na qual se insere este ensaio. 
Desse modo, tais informações precisam ser filtradas, como se diz, "precisamos separar o joio do trigo", sob o risco de não conseguirmos distinguir "mitos" de "verdades", "fantasia" de "realidade", "pânico" de "precaução" e produzirmos o "efeito manada", inclusive, transplantando para o contexto social mais amplo, sem a devida relativização, conclusões e resultados preliminares obtidos em contextos mais restritos e específicos, como ambientes laboratoriais controlados. Frente à falta de informações científicas claras, amplas e profundas, a máxima que orientou a estratégia adotada, pelo menos, no Brasil foi a de que é aceitável "errar pelo excesso" e, aparentemente, a de que "os fins justificam os meios" e, nesse viés, se os fins mais imediatos são validados como nobres, qualquer estratégia adotada é válida pra seu alcance, a despeito de suas iatrogenias de longo prazo, e, no futuro, tais estratégias poderão ser retomadas como medida mais viável, ao menor sinal de risco, sem uma avaliação acurada (a história já tem nos apontado essa tendência de comportamento), uma vez que foram legitimadas pela população acuada pela desinformação. Assim, suas consequências distantes no tempo ou mais sutis, como a saúde mental, principalmente, das crianças, estarão diluídas por outros eventos sociais que as camuflarão.

Medidas assim, decorrentes, em grande parte, de uma perspectiva flexneriana da saúde, transportam em suas premissas uma sutil negligência com o fator humano e social, em uma abordagem pouco antropológica de questões, por excelência, humanas, dentro de uma visão "biocêntrico-funcionalista", que parece ter se hegemonizado pelo mundo, na qual a função orgânica deve ser mantida ou recuperada, a despeito de quaisquer outros fatores ou consequências, sob o discurso de que vidas não se recuperam, mas se esquecendo de que uma vida salva hoje pode estar condenada amanhã por variáveis não consideradas, apropriadamente. Uma abordagem mais adequada poderia ser alcançada caso políticas educativas, prevencionistas e de investimento na Saúde Coletiva fossem adotadas como regra inalienável. O foco necessita ser a pessoa, não a doença, e esta pessoa precisa estar ciente de quais renúncias correspondem à sua escolha, para decidir, conscientemente, o que exige transparência de informações acerca das políticas adotadas. Para tanto, é necessário um planejamento de longo prazo e investimentos sociais na Educação, na Saúde e na Educação em Saúde, para o fortalecimento de sistemas como o SUS, a disseminação de informações fundamentadas, a construção de hábitos saudáveis de higiene pessoal e ambiental e a formação crítica do cidadão, para que atue de forma socialmente responsável, tecnicamente respaldada e politicamente comprometida. 
Para finalizar, sem a pretensão de concluir, importa nos preocuparmos com o saneamento das informações disponíveis, seja na esfera pública geral, seja no âmbito profissional e político dos tomadores de decisão, a partir de métodos científico válidos para um ancoramento da política em evidências contextualizadas na realidade do país. Apenas assim, seremos capazes de superar esta controvérsia na prática, com políticas públicas fundamentadas, efetivas, eficientes e eficazes, o quanto antes, em nome de um bem estar nacional (e global), trazendo para o debate variáveis ainda não consideradas ou consideradas apenas parcialmente e, discretamente, pontuadas neste ensaio à guisa de provocação do debate, pois o remédio não pode se tornar pior que a doença e o comportamento de manada não pode se sobrepor à racionalidade, em busca de salvarmos o maior número possível de vidas, agora e no futuro, onde nós, em um primeiro momento, e nossos filhos e netos, em momentos mais tardios, deveremos lidar com as consequências do que estamos fazendo hoje.

\section{REFERÊNCIAS BIBLIOGRÁFICAS}

ALMEIDA FILHO, N. Reconhecer Flexner: Inquérito sobre produção de mitos na educação médica no Brasil Contemporâneo. Cadernos De Saúde Pública, v. 26, n. 12, p. 2234-2249, 2010.

BRASIL. Ministério da Justiça e Segurança Pública. Gabinete do Ministro. Portaria Interministerial nº 5, de 17 de março de 2020. Dispõe sobre a compulsoriedade das medidas de enfrentamento da emergência de saúde pública previstas na Lei nº 13.979, de 06 de fevereiro de 2020. Diário Oficial da União, Edição Extra de 17/03/2020, n 52C (Página 1. Seção 1). 2020b.

BRASIL. Ministério da Saúde. Departamento de Assistência Farmacêutica e Insumos Estratégicos. Nota Informativa $n^{\circ}$ 5/2020-DAF/SCTIE/MS. Uso da Cloroquina como terapia adjuvante no tratamento de formas graves do COVID-19. Brasília, 2020d.

BRASIL. Ministério da Saúde. Secretaria de Vigilância em Saúde. Centro de Operações de Emergências em Saúde Pública. Plano de Contingência nacional para infecção Humana pelo novo Coronavírus CoVid-19. Brasília: MS/COE-COVID-19, 2020a. Acesso em 13Mar2020. Disponível em https://portalarquivos2.saude.gov.br/ images/pdf/2020/fevereiro/13/plano-contingencia-coronavirus-COVID19.pdf

BRASIL. Senado Federal. Decreto Legislativo $\mathrm{n}^{\circ}$ 6, de 2020. Reconhece, para os fins do art. 65 da Lei Complementar no 101, de 4 de maio de 2000, a ocorrência do estado de calamidade pública, nos termos da solicitação do Presidente da República encaminhada por meio da Mensagem $n^{\circ}$ 93, de 18 de março de 2020. Diário Oficial da União - Edição Extra de 20/03/2020 - nº 55-C. (p. 1, col. 1). 2020c

CHENG, Vincent C. C.; LAU, Susanna K. P.; WOO, Patrick C. Y.; YUEN, Kwok Yung. Severe Acute Respiratory Syndrome Coronavirus as an Agent of Emerging and Reemerging Infection. Clinical Microbiology Reviews, v. 20, n. 4, p. 660-694, 2007. DOI http://doi.org/10.1128/CMR.00023-07.

CRUZ, Felipe B. Qual é o recorde de frio no Brasil? E de calor?. Super Interessante. São Paulo: Abril, 2020. Acesso em 23Mar2020. Disponível em https://super.abril.com.br/mundo-estranho/qual-e-o-recorde-de-frio-no-brasile-de-calor/. 
DOMINGUÉZ, Nuno. Como o coronavírus se compara com a gripe? Os números dizem que ele é pior. El País. Madrid, 2020. Acesso em 13Mar2020. Disponível em https://brasil.elpais.com/ciencia/2020-03-03/como-ocoronavirus-se-compara-com-a-gripe-os-numeros-dizem-que-ele-e-pior.html.

FERGUSON, Neil M; LAYDON, Daniel; NEDJATI-GILANI, Gemma et al. Impact of non-pharmaceutical interventions (NPIs) to reduce COVID19 mortality and healthcare demand. Imperial College CoVID-19 Response Team, p. 120, 2020. DOI: https://doi.org/10.25561/77482.

FREUD, S. O mal-estar na civilização (Edição Standard Brasileira das Obras Psicológicas Completas de Sigmund Freud, Vol. 21). Rio de Janeiro: Imago, 1996. (Originalmente publicado em 1929)

IOANNIDIS, John P. A. A fiasco in the making? As the coronavirus pandemic takes hold, we are making decisions without reliable data. Stat News, mar/2020. Acesso em 25Mar2020. Disponível em https://www.statnews.com/2020/03/17/a-fiasco-in-the-making-as-the-coronavirus-pandemic-takes-hold-weare-making-decisions-without-reliable-data.

KAMPF, G.; TODT, D.; PFAENDER, S.; STEINMANN, E. Persistence of coronaviruses on inanimate surfaces and their inactivation with biocidal agentes. Journal of Hospital Infection, v.104, p. 246-251, 2020. Acesso em 23Mar2020. DOI https://doi.org/10.1016/j.jhin.2020.01.022.

KAPPES, Andreas; NUSSBERGER, Anne-Marie; FABER, Nadira S.; KAHANE, Guy; SAVULESCU, Julian; CROCKETT, Molly J. Uncertainty about the impact of social decisions increases prosocial behaviour. Nature Human Behaviour, 10pp, 2018. DOI https://doi.org/10.1038/s41562-018-0372-x.

MAMEDE, Walner. Modelo para avaliação de mestrados profissionais orientados à formação de recursos humanos para o SUS: Um estudo de caso. Tese (Doutorado) Instituto de Psicologia. Ensino na Saúde. Universidade de Brasília. Brasília/DF, 2016.

MAMEDE, Walner. Proposta de análise segundo a Teoria da Mudança: do Ciência Sem Fronteiras ao Programa Institucional de Internacionalização. Rev. Parcerias Estratégicas, v.24, n. 48, p. 133-150, 2019. Acesso em 13Mar2020. Disponível em http://seer.cgee.org.br/index.php/parcerias_estrategicas/article/viewFile/920/837.

MANCINI, Natália. Se proteja do coronavírus e dos boatos sobre ele. [Entrevista]. Rev. Abrale On-Line, 2020. Acesso em 13Mar2020. Disponível em https://www.abrale.org.br/revista-online/coronavirus-e-boatos-sobreele.

MERTON, Robert K. Science and Democratic Social Structure. In Social Theory and Social Structure. New York: Free Press, 1968. (pp. 604-615).

NUNES, E. Cem anos do Relatório Flexner. Ciênc. Saúde Coletiva, v. 15, n. 1, p. 956-956, 2010.

PAGLIOSA, F.; DA ROS, M. O relatório Flexner: Para o bem e para o mal. Revista Brasileira De Educação Médica, v. 32 n. 4, p. 492-499, 2008.

PATTON, Michael Q. Evaluation Implications of the Coronavirus Global Health Pandemic Emergency. Blue Marble Evaluation, march/2020. Acesso em 25Mar2020. Disponível em https://bluemarbleeval.org/latest/evaluation-implications-coronavirus-global-health-pandemic-emergency.

RAMOS, Andrea M.; ALVES, Lincoln; DINIZ, Assis F.; MARENGO, José A. Anuário Climático do Brasil: 2018. Instituto Nacional de Pesquisas Espaciais. Instituto Nacional de Meteorologia. Centro de Ciência do Sistema Terrestre. Centro Nacional de Monitoramento e Alertas de Desastres Naturais, 2018. Acesso em 23Mar2020. Disponível pdf/anuarioclima2018_Final.pdf.

TARANTINO, Mônica. Covid-19: Taxa de letalidade deve ser cinquenta ou talvez cem vezes menor do que a que vem sendo propagada. [Entrevista]. MedScape, 2020. Acesso em 13Mar2020. Disponível em https://portugues.medscape.com/verartigo/6504519. 
Quarentena da COVID-19 no Brasil: necessidade ou política do excesso contra o desconhecido? Uma crítica ao plano brasileiro de contingência, frente às orientações do relatório do Imperial College Team

TAYLOR, Steven. Psychology of Pandemics. Vancouver: Cambridge Scholars Publishing, 2019.

WHO-World Health Organization. Coronavirus disease 2019 (COVID-19): Situation Report 38. WHO, 2020b. Acesso 13Mar2020. Disponível em https://www.who.int/docs/default-source/coronaviruse/situationreports/20200227-sitrep-38-covid-19.pdf?sfvrsn=2db7a09b_4.

WHO-World Health Organization. Coronavirus disease 2019 (COVID-19): Situation Report 51. WHO, 2020c. Acesso 26Mar2020. Disponível em https://www.who.int/docs/default-source/coronaviruse/situationreports/20200311-sitrep-51-covid-19.pdf?sfvrsn=1ba62e57_10

WHO-World Health Organization. Coronavirus disease 2019 (COVID-19): Situation Report 79. WHO, 2020d. Acesso 08Abr2020. Disponível em https://www.who.int/docs/default-source/coronaviruse/situationreports/20200408-sitrep-79-covid-19.pdf?sfvrsn=4796b143_2

WHO-World Health Organization. Operational considerations for case management of COVID-19 in health facility and Community: Interim guidance. WHO, 2020a. Acesso 13Mar2020. Disponível em https://apps.who.int/iris/bitstream/ handle/10665/331492/WHO-2019-nCoV-HCF_operations-2020.1-eng.pdf

WU Z; MCGOOGAN JM. Characteristics of and Important Lessons From the Coronavirus Disease 2019 (COVID-19) Outbreak in China: Summary of a Report of 72314 Cases From the Chinese Center for Disease Control and Prevention. JAMA, feb/2020. DOI:10.1001/jama.2020.2648.

\section{(cc) EY}

Este trabalho está licenciado com uma Licença Creative Commons - Atribuição 4.0 Internacional. 